\title{
STATUS KEBERLANJUTAN PEMANFAATAN SUMBER DAYA IKAN BILIH DI DANAU TOBA (Tinjauan Aspek Ekonomi dan Sosial)
}

\author{
Yesi Dewita Sari dan Sonny Koeshendrajana \\ Balai Besar Riset Sosial Ekonomi Kelautan dan Perikanan \\ JI. KS. Tubun Petamburan VI Jakarta 10260 \\ Telp. (021) 53650162, Fax. (021)53650159 \\ Diterima 14 Maret 2011 - Disetujui 21 Mei 2011
}

\begin{abstract}
ABSTRAK
Penelitian ini bertujuan untuk mengkaji status keberlanjutan pemanfaatan sumber daya ikan bilih (Mystacoleucus padangensis Bleeker) di Danau Toba dan faktor-faktor yang mempengaruhi keberlanjutan tersebut. Penelitian dilakukan pada tahun 2010 di beberapa tempat sentra pendaratan ikan bilih, antara lain: Kabupaten Simalungun, Kabupaten Toba Samosir, Kabupaten Dairi, Kabupaten Karo dan Kabupaten Samosir. Data yang digunakan terdiri dari data primer dan data sekunder, sedangkan analisis dilakukan dengan menggunakan Metode RAPFISH. Atribut ekonomi yang digunakan untuk mengetahui status keberlanjutan terdiri dari tingkat keuntungan, kontribusi perikanan terhadap PDRB, penyerapan tenaga kerja, sifat kepemilikan sarana produksi, tingkat subsidi, alternatif pekerjaan dan pendapatan bagi pelaku perikanan dan besarnya jangkauan pemasaran ikan bilih. Atribut sosial terdiri dari pertumbuhan komunitas nelayan, status konflik, tingkat pendidikan, pengetahuan lingkungan, banyaknya penyuluhan dan keikutsertaan dalam kelompok. Hasil analisis menunjukkan bahwa pemanfaatan sumber daya ikan bilih di Danau Toba kurang berkelanjutan baik ditinjau dari aspek ekonomi maupun aspek sosial. Indeks keberlanjutan dari aspek ekonomi adalah $46,36 \%$ dan keberlanjutan dari aspek sosial adalah $31,27 \%$. Status keberlanjutan dalam kategori kurang ini, mengharuskan adanya campur tangan dari pihak pengelola Danau Toba untuk menerapkan opsi pengelolaan yang dapat menjamin keberlanjutan ikan bilih yang di Danau Toba.
\end{abstract}

Kata Kunci: ikan bilih, danau toba, rapfish,status keberlanjutan

\section{Abstract : Sustainability Status of Bilih Fish Exploitation in Toba Lake (Review of Social and Economic Aspects) by: Yesi Dewita Sari dan Sonny Koeshendrajana}

This study aims to asses sustainability status of the of Bilih Fish resources in the lake Toba and factors affecting the sustainability of this. Research was carried out in 2010 in several conters of Bilih Fish landing place, among others the districts of Simalungun, Toba Samosir, Dairi, Karo and Samosir. Primary and secondary data were used; while analysis was carried out using RAPFISH method. Economic attibute being used to asses sustainability status of the resource were profit, contribution of fisheries to gross domestic product (GDP), employment, nature ownership of production factors, level of subsidy, employment and income alternatives and marketing. Social attributes consist of the growth of fishing communities, conflict status, education level, environmental knowledge, number of extention worker and participation in the group. Results show that the utilization of Bllih fish resource in Lake Toba are relatively unsustainable interms of economic and social aspects. Index of economic aspects sustainability in 46,36\% and social aspects sustainability in $31,27 \%$. These indice indicate that the fisheries status was insustainable. This, inturn, needs intervention from Lake Toba mangement authority to manage in such away so that sustainability of Bilih fish are ensure.

Keywords: Bilih fish, Toba Lake, RAPFISH and Sustainability Status 


\section{PENDAHULUAN}

Ikan bilih (Mystacoleucus padangensis Bleeker) merupakan ikan endemik yang hidup di Danau Singkarak, Sumatera Barat. Ikan ini merupakan salah satu komoditas andalan bagi nelayan di Danau Singkarak Kabupaten Tanah Datar dan Solok Provinsi Sumatra Barat dan mampu menopang aktifitas perekonomian di sekitar Danau Singkarak. Ikan bilih dapat memijah dan berkembang biak secara alami jika sepanjang daerah pemijahan dan asuhan anakannya dilindungi. Secara ringkas dapat dikatakan bahwa ikan ini mampu berkembang biak dengan cepat apabila hábitat kehidupan ikan atau kondisi lingkungan sumberdaya perairan tempat ikan tersebut sesuai.

Perikanan di Danau Toba pernah mengalami krisis populasi ikan asli (seperti: ikan batak, Neolissochilus thienemanni; dan ikan pora-pora, Puntius binotatus) sebagai akibat dari hasil penebaran ikan mujair (Oreochromis mossambicus) dan nila (Oreochromis niloticus) serta diduga sebagai dampak negatif dari peningkatan aktivitas penangkapan serta penurunan kualitas lingkungan perairan. Berbagai upaya rehabilitasi populasi ikan batak telah dilakukan dengan cara penebaran kembali (re-stocking) benih ikan hasil pemijahan, namun belum menunjukkan hasil yang menggembirakan. Hasil kajian yang dilakukan oleh Sarnita dan Kartamihardja (2008) tentang kondisi lingkungan perairan di Danau Toba serta karakteristik ikan bilih menunjukkan bahwa ikan bilih dapat ditebar di perairan Danau Toba tanpa merusak struktur komunitas stok ikan di perairan tersebut. Oleh karena itu, untuk meningkatkan produksi ikan bilih dan mengoptimalkan pemanfaatan sumber daya di Danau Toba, maka pada tahun 2003 dilakukan penebaran (introduksi) ikan bilih sebanyak 2.840 ekor. Benih ikan bilih ini diambil dari Danau Singkarak (Koeshendrajana et al., 2010).

Perkembangan ikan bilih di Danau Toba menunjukkan hasil yang menggembirakan.
Nelayan sudah dapat melakukan penangkapan sejak tahun 2005. Produksi ikan bilih ini menunjukkan semakin meningkat mulai tahun 2005 sampai dengan tahun 2009. Produksi ikan bilih telah melebihi jumlah produksi ikan dominan lainnya seperti mujair dan nila. Semenjak akhir tahun 2009 sampai dengan tahun 2010, produksi ikan bilih menunjukkan penurunan, bahkan pada beberapa sentra pendaratan ikan sudah tidak ditemukan ikan bilih sama sekali. Penurunan jumlah produksi ini diduga karena adanya penggunaan alat tangkap dan operasi penangkapan ikan yang tidak ramah lingkungan. Selain itu juga diduga adanya perubahan musim, sehingga terjadi penurunan jumlah produksi dalam tahun terakhir ini. Oleh karena itu perlu dilakukan analisis status keberlanjutan pemanfaatan ikan bilih di Danau Toba serta faktor yang berpengaruh terhadap keberlanjutan tersebut.

\section{METODOLOGI}

\section{Lokasi dan Waktu Penelitian}

Lokasi penelitian dilakukan di Danau Toba khususnya di sentra-sentra pendaratan ikan di Kabupaten Simalungun, Kabupaten Toba Samosir, Kabupaten Dairi, Kabupaten Karo dan Kabupaten Samosir pada bulan Oktober 2010 (Gambar 1).

\section{Jenis, Sumber dan Cara Pengumpulan Data}

Jenis data yang digunakan dalam penelitian ini terdiri dari data primer dan sekunder. Data primer berupa jenis alat tangkap yang digunakan, jumlah hasil tangkapan, harga ikan, cakupan pemasaran, kemungkinan konflik antar nelayan, tingkat pendidikan nelayan, tingkat pengetahuan nelayan terhadap pelestarian lingkungan, partisipasi nelayan dalam mengikuti penyuluhan dan pembentukan kelompok. Data primer diperoleh melalui pengamatan terhadap beberapa obyek dilapangan dan wawancara dengan nelayan dan informan kunci. 


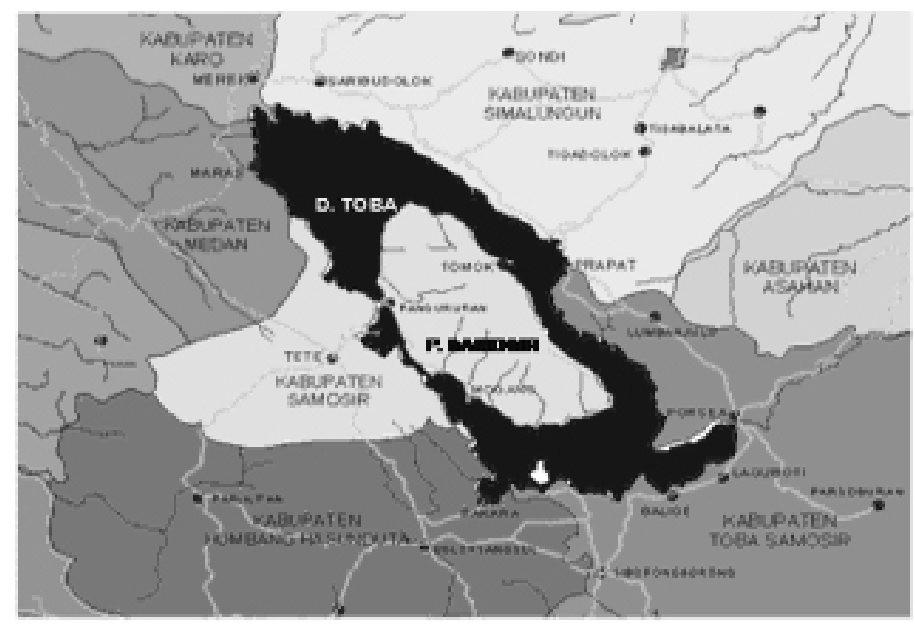

Gambar 1. Lokasi Penelitian

Figure 1 Research Area

Data sekunder berupa perkembangan produksi ikan bilih, perkembangan jumlah nelayan, jenis mata pencaharian masyarakat disekitar Danau Toba, tingkat pendidikan serta beberapa lainnya yang terkait dengan topik penelitian. Data sekunder diperoleh melalui penelusuran literatur baik dari lembaga penelitian lingkup Kementerian Kelautan dan Perikanan, Perguruan Tinggi maupun Dinas Teknis terkait di daerah.

\section{Metode Analisis Data}

Metode analisis data yang digunakan untuk mengetahui status keberlanjutan pemanfaatan ikan bilih di Danau Toba adalah analisis penskalaan multidimensi atau multidimensional scaling (MDS). MDS adalah teknik statistik yang mencoba melakukan transformasi multi dimensi kedalam dimensi yang lebih rendah (Fauzi dan Anna, 2005). Berdasarkan ketersediaan data dan cakupan penelitian yang dilakukan pada tahun 2010, dimensi yang digunakan untuk mengetahui keberlanjutan pemanfaatan sumber daya ikan bilih di Danau Toba ditinjau dari dimensi ekonomi dan sosial. Atribut dalam dimensi ekonomi meliputi tingkat keuntungan yang diperoleh dari usaha ikan bilih, kontribusi perikanan terhadap PDRB, penyerapan tenaga kerja, status kepemilikan aset usaha, pemberian subsidi oleh pemerintah, alternatif untuk mendapatkan pekerjaan dan sumber pendapatan lainnya serta jangkauan pemasaran ikan bilih. Atribut dalam dimensi sosial meliputi pertumbuhan jumlah nelayan, status konflik, tingkat pendidikan, pengetahuan lingkungan, upaya perbaikan ekosistem, perbandingan biaya hidup terhadap total pendapatan, partisipasi keluarga, frekuensi penyuluhan dan frekuensi pertemuan warga. Atribut yang ada diberikan skor yang mengacu kepada skor RAPFISH dengan menyesuaikan pada kondisi yang diperoleh dari hasil penelitian.

Seluruh atribut yang digunakan dan telah diberi skor berdasarkan data dan fakta yang diperoleh kemudian dianalisis secara MDS. Dengan metode MDS, obyek atau titik yang diamati dipetakan dalam ruang dua atau tiga dimensi, sehingga obyek atau titik tersebut diupayakan sedekat mungkin dengan titik asal. Sebaliknya titik yang tidak sama digambarkan dengan titik-titik yang berjauhan. Teknik ordinasi (penentuan jarak) di dalam MDS didasarkan pada Euclidian distance yang dalam ruang yang berdimensi $n$ dapat ditulis sebagai berikut (Fauzi dan Anna, 2005):

$$
d=\sqrt{\left(x 1-\left.x 2\right|^{2}+|y 1-y 2|^{2}+\mid z 1-z 2^{2}+\ldots\right)}
$$


Tabel 1. Skor dan Acuan Penentuan Skor Masing-Masing Atribut yang Digunakan dalam Keberlanjutan Pemanfaatan Ikan Bilih di Danau Toba, 2010

Table 1. Score and Reference Score for Each Attributes Used in the Studyof Sustainability Status of Bilih Fish Exploitation in Toba Lake, 2010

\begin{tabular}{|c|c|c|c|c|}
\hline Atribut/Attributes & $\begin{array}{l}\text { Skor/ } \\
\text { Score }\end{array}$ & Baik/Good & Buruk/Bad & Keterangan \\
\hline \multicolumn{5}{|l|}{ Ekonomi/Economic } \\
\hline Keuntungan/Profit & $\begin{array}{c}0 ; 1 ; 2 ; \\
3 ; 4\end{array}$ & 0 & 4 & $\begin{array}{l}\text { RAPFISH : (0) sangat } \\
\text { menguntungkan/ } \\
\text { highly profitable; (1) } \\
\text { menguntungkan/profitable; } \\
\text { (2) kembali modal atau } \\
\text { impas/ breakeven; (3) rugi } \\
\text { sedikit/ little loss; (4) sangat } \\
\text { merugi /loss }\end{array}$ \\
\hline $\begin{array}{l}\text { Kontribusi perikanan } \\
\text { terhadap Produk Domestik } \\
\text { Regional Bruto(PDRB)/ } \\
\text { Fishery contributions to } \\
\text { Gross Domestic Product } \\
\text { (GDP) }\end{array}$ & $0 ; 1 ; 2$ & 2 & 0 & $\begin{array}{l}\text { RAPFISH : (0) rendah/low; (1) } \\
\text { sedang/medium; (2) tinggi/ } \\
\text { high }\end{array}$ \\
\hline $\begin{array}{l}\text { Penyerapan tenaga kerja/ } \\
\text { Employment rates }\end{array}$ & $0 ; 1 ; 2$ & 2 & 0 & $\begin{array}{l}\text { RAPFISH : (0) rendah/low; (1) } \\
\text { sedang/medium; (2) tinggi/ } \\
\text { high }\end{array}$ \\
\hline $\begin{array}{l}\text { Kepemilikan/Ownership } \\
\text { (penerima keuntungan dari } \\
\text { kepemilikan) }\end{array}$ & $0 ; 1 ; 2$ & 0 & 2 & $\begin{array}{l}\text { RAPFISH : (0) pemilik local/ } \\
\text { local owner; (1) pemilik local } \\
\text { non local/ local and non local } \\
\text { owner; (2) pemilik non local/ } \\
\text { non local owner }\end{array}$ \\
\hline $\begin{array}{l}\text { Tingkat subsidi/ } \\
\text { Subsidies rate }\end{array}$ & $\begin{array}{l}0 ; 1 ; 2 \\
3 ; 4\end{array}$ & 0 & 4 & $\begin{array}{l}\text { RAPFISH : }(0) \text { tidak ada/ } \\
\text { nothing; }(1) \text { sedikit/ } \\
\text { rare; }(2) \text { besar/big; }(3) \\
\text { sangat tergantung/highly } \\
\text { dependent; }(4) \text { keharusan } \\
\text { mutlak/absolute dependence }\end{array}$ \\
\hline $\begin{array}{l}\text { Alternatif pekerjaan dan } \\
\text { pendapatan/Alternative } \\
\text { livelihood and income }\end{array}$ & $0 ; 1 ; 2$ & 2 & 0 & $\begin{array}{l}\text { RAPFISH : (0) tidak ada/ } \\
\text { nothing; (1) ada sedikit/little; } \\
\text { (2) ada banyak/many }\end{array}$ \\
\hline $\begin{array}{l}\text { Besarnya pemasaran } \\
\text { perikanan/ Fish market } \\
\text { distribution }\end{array}$ & $0 ; 1 ; 2$ & 2 & 0 & $\begin{array}{l}\text { RAPFISH : (0) pasar lokal/ } \\
\text { local market; (1) pasar } \\
\text { nasional/national market; } \\
\text { (2) pasar internasional / } \\
\text { international market }\end{array}$ \\
\hline \multicolumn{5}{|l|}{ Sosial/Social } \\
\hline $\begin{array}{l}\text { Pertumbuhan nelayan } \\
\text { pengeksploitasi perikanan/ } \\
\text { The growth of fisher } \\
\text { population }\end{array}$ & $\begin{array}{l}0 ; 1 ; \\
2 ; 3\end{array}$ & 0 & 3 & $\begin{array}{l}\text { RAPFISH: }(0)<10 \% ;(1) 10- \\
20 \% ;(2) 20-30 \% ;(3)>30 \%\end{array}$ \\
\hline
\end{tabular}




\section{Lanjutan Tabel 1/Continues Table 1}

\begin{tabular}{|c|c|c|c|c|}
\hline Atribut/Attributes & $\begin{array}{l}\text { Skor/ } \\
\text { Score }\end{array}$ & Baik/Good & Buruk/Bad & Keterangan \\
\hline $\begin{array}{l}\text { Status konflik / Conflict } \\
\text { status }\end{array}$ & $0 ; 1 ; 2$ & 0 & 2 & $\begin{array}{l}\text { (0) tidak berpengaruh/ no } \\
\text { effect; ( } 1 \text { ) biasa/usual effect; } \\
\text { (2) berat }\end{array}$ \\
\hline $\begin{array}{l}\text { Tingkat pendidikan/ } \\
\text { Education level }\end{array}$ & $0 ; 1 ; 2$ & 2 & 0 & $\begin{array}{l}\text { RAPFISH : (0) rendah/low; (1) } \\
\text { sedang/medium; (2) tinggi / } \\
\text { high }\end{array}$ \\
\hline $\begin{array}{l}\text { Pengetahuan lingkungan / } \\
\text { Environmental knowledge }\end{array}$ & $0 ; 1 ; 2$ & 2 & 0 & $\begin{array}{l}\text { RAPFISH : (0) sangat minim/ } \\
\text { very minimal; }(1) \text { cukup/ } \\
\text { enough; }(2) \text { sangat luas / } \\
\text { highly }\end{array}$ \\
\hline $\begin{array}{l}\text { Biaya hidup terhadap } \\
\text { total pendapatan / Cost of } \\
\text { living comparison to total } \\
\text { revenue }\end{array}$ & $0 ; 1 ; 2$ & 0 & 2 & $\begin{array}{l}\text { RAPFISH : }(0)<50 \% ;(1) 50- \\
80 \% ;(2)>80 \%\end{array}$ \\
\hline $\begin{array}{l}\text { Upaya perbaikan ekosistem } \\
\text { / Efforts to ecosystems } \\
\text { rehabilitation }\end{array}$ & $0 ; 1 ; 2$ & 2 & 0 & $\begin{array}{l}\text { RAPFISH : (0) tidak ada/ } \\
\text { nothing; (1) jarang/ rare; ( } 2) \\
\text { sering/often }\end{array}$ \\
\hline $\begin{array}{l}\text { Partisipasi keluarga dalam } \\
\text { pemanfaatan sumberdaya } \\
\text { perikanan / Family } \\
\text { participation to fishery } \\
\text { exploitation }\end{array}$ & $\begin{array}{l}0 ; 1 ; \\
2 ; 3\end{array}$ & 3 & 0 & $\begin{array}{l}\text { RAPFISH: (0) tidak ada/ } \\
\text { nothing; (1) 1-2 anggota } \\
\text { keluarga/1-2 of family crew; } \\
\text { (2) 3-4 anggota keluarga/3-4 } \\
\text { of familiy crew; (3) lebih dari } \\
5 \text { orang anggota keluarga/ } \\
\text { more than } 5 \text { of family crew }\end{array}$ \\
\hline $\begin{array}{l}\text { Frekuensi penyuluhan dan } \\
\text { pelatihan/ Frequency of } \\
\text { counseling and training }\end{array}$ & $\begin{array}{l}0 ; 1 ; 2 ; \\
3 ; 4\end{array}$ & 4 & 0 & $\begin{array}{l}\text { RAPFISH : (0) tidak pernah } \\
\text { ada/never; (1) sekali dalam } \\
5 \text { tahun/ once in } 5 \text { years; ( } 2 \text { ) } \\
\text { sekali dalam } 1 \text { tahun/once } \\
\text { in a year; ( } 3 \text { ) dua kali dalam } \\
\text { satu tahun/ twice in a year; } \\
\text { (4) lebih dari } 3 \text { kali dalam } \\
\text { satu tahun/ more than } 3 \\
\text { times a year }\end{array}$ \\
\hline $\begin{array}{l}\text { Frekuensi pertemuan } \\
\text { antar warga berkaitan } \\
\text { pengelolaan sumberdaya } \\
\text { perikanan/ Frequency of } \\
\text { community meeting for } \\
\text { resource management }\end{array}$ & $\begin{array}{l}0 ; 1 ; 2 \\
3 ; 4\end{array}$ & 4 & 0 & $\begin{array}{l}\text { RAPFISH : (0) tidak pernah } \\
\text { ada/never; (1) sekali dalam } \\
5 \text { tahun/once in } 5 \text { years; ( } 2 \text { ) } \\
\text { sekali dalam } 1 \text { tahun/once } \\
\text { in a year; (3) dua kali dalam } \\
\text { satu tahun/ twice in a year; } \\
\text { (4) lebih dari } 3 \text { kali dalam } \\
\text { satu tahun/ more than } 3 \\
\text { times a year }\end{array}$ \\
\hline
\end{tabular}

Sumber : Susilo, 2003 /source : Susilo, 2003 
Konfigurasi atau ordinasi dari suatu obyek atau titik dalam MDS kemudian diaproksimasi dengan meregresikan jarak euclidian $\left(\mathrm{d}_{\mathrm{ij}}\right.$ ) dari titik $\mathrm{i}$ ke titik $\mathrm{j}$ dengan titik asal $\left(d_{i j}\right)$ sebagaimana dalam persamaan:

$$
d_{i j}=a+b d_{i j}+e
$$

Teknik regresi yang digunakan adalah algoritma ALSCAL yang biasa digunakan pada software statistika (Alder et al. dalam Fauzi dan Anna, 2005). Metode ALSCAL mengoptimalisasi jarak kuadrat (square distance $=\mathrm{d}_{\mathrm{ijk}}$ ) terhadap data kuadrat (titik asal $=\mathrm{O}_{\mathrm{ijk}}$ ) yang dalam tiga dimensi ditulis dalam formula yang disebut S-Stress sebagai berikut:

$S=\sqrt{\frac{1}{m}} \sum_{k=1}^{m}\left[\frac{\sum_{i} \sum_{j}\left(d_{i j k}^{2}-O_{i j k}^{2}\right)^{2}}{\sum_{i} \sum_{j} O_{i j k}^{4}}\right]$

Dimana jarak kuadrat merupakan jarak euclidian yang dibobot, atau ditulis :

$$
d_{i j k}^{2}=\sum_{a=1}^{r} w_{k a}\left(x_{i a}-x_{j a}\right)^{2}
$$

Pada setiap pengukuran yang bersifat mengukur (metric) seberapa fit (goodness of fit), jarak titik pendugaan dengan titik asal menjadi sangat penting. Goodness of fit dalam MDS adalah mengukur seberapa tepat (how well) konfigurasi dari suatu titik dapat mencerminkan data aslinya. Hal ini dicerminkan dari besaran nilai $S$-Stress yang dihitung berdasarkan nilai $\mathrm{S}$ diatas. Nilai S yang rendah menunjukkan good fit sementara nilai $S$ yang tinggi menunjukkan sebaliknya. Didalam MDS model, nilai S yang baik adalah lebih kecil dari 0,25.

Untuk memudahkan penentuan status keberlanjutan pemanfaatan ikan bilih di Danau Toba, maka selang dari bad (0) sampai good (100) tersebut dibagi menjadi beberapa kategori atau status, yaitu dengan membagi empat selang 0-100 tersebut. Selang indeks keberlanjutan tersebut yaitu selang 0-25 dalam status buruk, selang 26-50 dalam status kurang, selang 51-75 dalam status cukup dan selang 76-100 dalam status baik. Menurut Susilo (2003), pembagian selang yang menggambarkan status indeks keberlanjutan dapat dilihat pada Tabel 2 .

Tabel 2. Selang Indeks dan Status Keberlanjutan Perikanan dalam pemanfaatan Ikan Bilih di Danau Toba, $\mathbf{2 0 1 0}$

Table 2. Index Rangers and Status of Fisheries Sustainability of Sustainability Status of Bilih Fish Exploitation in Toba Lake, 2010

\begin{tabular}{ccc}
\hline No & $\begin{array}{c}\text { Selang Indeks } \\
\text { Keberlanjutan/ } \\
\text { Sustainability } \\
\text { Index Ranges }\end{array}$ & $\begin{array}{c}\text { Status } \\
\text { Keberlanjutan/ } \\
\text { Sustainability Status }\end{array}$ \\
\hline 1 & $0-25$ & Buruk/bad \\
2 & $26-50$ & Kurang/less \\
3 & $51-75$ & Cukup/enough \\
4 & $76-100$ & Baik/good \\
\hline
\end{tabular}

Sumber: Susilo, 2003/ Source: Susilo, 2003

Setelah nilai indeks keberlanjutan pemanfaatan ikan bilih di Danau Toba diketahui, selanjutnya dilakukan analisis sensitifitas dengan menggunakan analisis Leverage. Analisis Leverage adalah analisis statistik untuk mengetahui pengaruh parameter-parameter di setiap atribut yang digunakan untuk mengetahui indeks keberlanjutan. Dengan menggunakan metode analisis ini akan dapat diketahui parameter-parameter kunci yang paling berpengaruh (baik bersifat mendukung maupun menghambat) terhadap penentuan indeks keberlanjutan pemanfaatan ikan bilih di Danau Toba.

\section{HASIL DAN PEMBAHASAN}

\section{Potret Ikan Bilih (Mystacoleucus padangensis) di Danau Toba}

Danau Toba terletak di Provinsi Sumatera Utara dan secara administratif mencakup 6 (enam) kabupaten 1 kota, yakni Samosir, Toba Samosir, Dairi, Karo, Simalungun, Humbang 
Hasunduta dan Kota Medan. Kegiatan perikanan di perairan Danau Toba didominasi oleh kegiatan penangkapan ikan skala kecil. Kegiatan usaha penangkapan dilakukan oleh nelayan dengan menggunakan armada penangkapan yang cukup sederhana, yakni menggunakan perahu tanpa motor dan perahu motor tempel dengan jenis alat tangkap berupa jaring insang (gillnet), pancing baik berupa pancing rawai (longlines) maupun pancing biasa (hooklines), bubu (trap) dan bagan (lift net). Beberapa tempat pendaratan ikan tersedia di sekitar perairan Danau Toba, antara lain di Parapat, Tongging, Porsea, Balige dan Silalahi dan pendaratan di Pulau Samosir terdapat di Pangaruran dan Palipi. Jenis ikan tertangkap didominasi oleh ikan bilih (Mystacoleucus padangensis), mujaer (Oreochromis mossambicus) dan nila (Oreochromis niloticus).

Ikan bilih (Mystacoleucus padangensis) di Danau Toba merupakan ikan hasil introduksi (penebaran) yang dilakukan oleh Pusat Riset Perikanan Tangkap (Badan Litbang KP) pada tahun 2003, tepatnya pada tanggal 3 Januari tahun 2003. Ikan bilih ini ditebar di Danau Toba sebagai upaya pengkayaan stok ikan yang telah ada di badan air tersebut; disamping itu, ikan ini ditebar untuk mengganti keberadaan ikan pora-pora yang pernah ada di perairan Danau Toba. Habitat asli ikan bilih adalah di perairan Danau Singkarak, Sumatera Barat. Ikan bilih bersifat endemik di Danau Singkarak, artinya secara geografis penyebarannya sangat terbatas di dunia dan dilaporkan oleh Kotelat et al. (1993) hanya di temui di Danau Singkarak, Sumatera Barat.Kartamihardja (2009) menyatakan bahwa sesuai dengan sifat ikan bilih sebagai ikan endemik, sangat rentan terhadap kepunahan sebagai akibat dari kerusakan habitat maupun kegiatan eksploitasi penangkapan yang dilakukan oleh masyarakat.

Ikan bilih ditebar di daerah Parapat dan Ajibata di Danau Toba - Sumatra Utara sebanyak 2.840 ekor pada tanggal 3 Januari 2003. Dalam perkembangannya, ternyata jenis ikan ini mampu tumbuh dan berkembang biak dengan pesat; masyarakat nelayan sekitar Danau Toba menyebutnya sebagai ikan pora-pora atau ikan 'Mega'.
Penamaan ikan bilih sebagai ikan pora-pora berdasarkan pemahaman masyarakat bahwa jenis ikan tersebut mirip ikan pora-pora yang dulu (sebelum 1990) pernah ada di perairan Danau Toba. Penamaan ikan 'Mega' didasarkan pemahaman masyarakat bahwa jenis ikan ini ditebar pada masa pemerintahan Presiden Megawati. Perkembangan ikan bilih yang ada di Danau Toba ini bahkan dilaporkan melebihi keragaan pertumbuhan dan perkembangan pada habitat aslinya di Danau Singkarak.

\section{Atribut RAPFISH pada Aspek Ekonomi}

\section{Keuntungan Penangkapan Ikan Bilih}

Kegiatan usaha dalam pemanfaatan sumber daya ikan bilih di Danau Toba meliputi usaha penangkapan, pengolahan dan pemasaran. Penangkapan ikan bilih dilakukan dengan menggunakan alat tangkap gillnet, bagan, jala dan bubu. Bentuk olahan ikan bilih yaitu ikan bilih kering dan goreng, namun pada saat penelitian dilakukan hanya diperoleh responden pengolah ikan bilih menjadi ikan bilih kering. Pemasaran ikan bilih tidak hanya diseputar Danau Toba, tetapi telah mencakupi sebagian besar seluruh Pulau Sumatera untuk ikan bilih segar dan Jakarta untuk ikan bilih olahan. Usaha penangkapan ikan bilih yang dilakukan oleh masyarakat memberikan keuntungan dengan $\mathrm{R} / \mathrm{C}$ lebih dari 3 dan profitabilitas lebih dari 2 (disajikan pada Tabel 3). Berdasarkan uraian tersebut atribut keuntungan diberikan skor (1) yaitu menguntungkan bagi pelaku usaha

\section{Kontribusi Perikanan Bilih (Mystacoleucus Padangensis Blkr) Terhadap PDRB}

Ikan bilih di Danau Toba berkembang biak dengan cepat, dan bahkan lebih cepat dibandingkan habitat aslinya di Danau Singkarak (Sarnita dan Kartamihardja, 2008). Estimasi total hasil tangkapan ikan bilih oleh nelayan adalah 1.766 ton per tahun yang diperhitungkan berdasarkan rataan tangkap ikan Bilih per hari sebesar 1,75 ton/hari di Parapat, 2,25 ton/hari di Tongging, 0,75 ton/ 
Tabel 3. Keuntungan Usaha Penangkapan Ikan Bilih di Danau Toba, 2010 Table 3. Business Profit of Bilih Fishing in Toba Lake, 2010

\begin{tabular}{|c|c|c|c|c|}
\hline \multirow[b]{2}{*}{ Uraian/item } & \multirow{2}{*}{$\begin{array}{c}\text { Jaring insang/ } \\
\text { Gillnet }\end{array}$} & \multirow{2}{*}{$\begin{array}{c}\text { Jala dan Bubu/ } \\
\text { trap }\end{array}$} & \multicolumn{2}{|c|}{ Doton/Bagan } \\
\hline & & & $\begin{array}{c}\text { Ukuran } 15 \times 15 / \\
\text { size } 15 \times 15\end{array}$ & $\begin{array}{c}\text { Ukuran } 20 \times 20 / \\
\text { size } 20 \times 20\end{array}$ \\
\hline $\begin{array}{l}\text { Keuntungan (Rp)/ } \\
\text { Profit (Rp) }\end{array}$ & 58.554 & 68.032 & 386.698 & 927.142 \\
\hline $\mathrm{R} / \mathrm{C}$ & 3,02 & 3,13 & 4,41 & 8,55 \\
\hline $\begin{array}{l}\text { Profitabilitas/ } \\
\text { Profitabilitas }\end{array}$ & 2,02 & 2,13 & 3,41 & 7,55 \\
\hline
\end{tabular}

Sumber: Data Primer tahun 2010, Diolah / Source: Primary Data 2010, Processed

hari di Porsea dan 1,75 ton/hari di Balige. Angka estimasi ini dibuat mengingat sistem pencatatan statistik yang ada belum dapat memberikan angka-angka produksi ikan bilih di Danau Toba. Jumlah produksi ikan bilih ini boleh dikatakan cukup besar, tetapi karena harga sangat rendah yaitu berkisar Rp. 1.500-2.000 per kg memberikan nilai produksi yang kecil. Dengan demikian dapat dikatakan bahwa ikan bilih di Danau Toba memberikan kontribusi yang rendah terhadap PDRB Kabupaten. Skor untuk kontribusi perikanan bilih terhadap PDRB adalah nol (0).

\section{Penyerapan Tenaga Kerja}

Sebelum adanya ikan bilih di Danau Toba, mata pencaharian masyarakat di sekitar Danau Toba adalah sebagai nelayan dan petani. Dengan adanya ikan bilih dalam jumlah yang besar semenjak tahun 2005, jumlah nelayan mengalami peningkatan. Hal ini terjadi karena sebagian petani yang mempunyai kebun di sekitar Danau Toba mencoba berusaha untuk memanfaatkan ikan bilih dengan menggunakan alat tangkap yang sederhana. Skor untuk atribut penyerapan tenaga kerja menjadi nelayan ikan bilih di Danau Toba adalah satu (1).

\section{Kepemilikan}

Usaha penangkapan ikan bilih dilakukan oleh nelayan yang bertempat tinggal di sekitar Danau Toba. Alat tangkap dan armada penangkapan yang digunakan pada umumnya bersifat tradisional dengan teknologi rendah. Hanya alat tangkap bagan/doton yang memerlukan modal atau investasi lebih dari 20 juta. Permodalan untuk alat tangkap gillnet dan jala serta bubu bersumber dari nelayan itu sendiri, sedangkan untuk alat tangkap bagan diperoleh dari pedagang pengumpul atau pedagang besar. Pengolah ikan menjadi ikan bilih kering adalah masyarakat di sekitar Danau Toba, sedangkan pengolah untuk mendapatkan ikan bilih kering berasal dari daerah lain. Pada umumnya engolah ikan bilih menjadi ikan bilih goreng adalah pengolah dari Sumatera Barat yang telah mempunyai pengalaman dan pemasaran terhadap produk ikan bilih goreng.

Pedagang pengumpul ikan bilih adalah masyarakat sekitar Danau Toba yang memiliki modal lebih besar untuk menjadi pedagang pengumpul. Pedagang besar yang mengumpulkan dan memasarkan ikan dari pedagang pengumpul berasal dari luar daerah. Pedagang besar ini membuat ikatan dagang dengan pedagang pengumpul dan nelayan dengan memberikan bantuan modal untuk menjadi pedagang dan untuk menjadi nelayan pengguna alat tangkap bagan. Berdasarkan informasi tersebut, penerima keuntungan dari pemanfaatan sumber daya ikan bilih di Danau Toba adalah pemilik lokal dan pendatang atau skor nol (0). 


\section{Tingkat Subsidi}

Berdasarkan informasi dari nelayan responden, diketahui bahwa nelayan yang melakukan penangkapan ikan bilih di Danau Toba belum mendapatkan bantuan atau subsidi dari pemerintah. Nelayan membutuhkan bantuan modal, bantuan teknologi penangkapan dan aturan-aturan pengelolaan. Sampai dengan dilakukan penelitian ini belum terlihat adanya perhatian dari pemerintah daerah dalam pengelolaan ikan bilih di Danau Toba. Skor untuk atribut tingkat subsidi adalah nol (0) atau tidak ada

\section{Alternatif pekerjaan dan pendapatan}

Berdasarkan hasil wawancara dengan responden di lokasi penelitian, adanya ikan bilih ini telah memberikan lapangan pekerjaan baru bagi masyarakat dengan sambilan menjadi petani. Semakin berkurangnya jumlah produksi ikan bilih dan harga yang rendah, menyebabkan masyarakat kehilangan mata pencaharian. Sebagian besar responden mengharapkan untuk dilakukan penebaran kembali, sehingga nelayan dapat kembali hidup seperti tahun 2005-2008. Dengan demikian dapat dikatakan bahwa nelayan ikan bilih di Danau Toba tidak memiliki alternatif mata pencaharian lain, sehingga skor untuk atribut alternatif pekerjaan dan pendapatan bagi pelaku perikanan di Danau Toba adalah nol (0).

\section{Besarnya Pemasaran}

Ikan bilih merupakan ikan endemik di Danau Singkarak Sumatera Barat yang di introduksi ke Danau Toba pada tahun 2003. Masyarakat yang telah mengenal adanya ikan bilih ini adalah masyarakat di sekitar Sumatera Barat seperti Riau, Jambi, Bengkulu dan Palembang. Produksi ikan bilih di Danau Singkarak mengalami penurunan karena pemanfaatan dan pengelolaan yang tidak ramah. Oleh karena itu, produksi ikan bilih di danau Toba dapat memanfaatkan permintaan pasar ikan bilih yang telah ada di sekitar wilayah Sumatera Barat tersebut.
Selain itu, untuk produk ikan olahan telah merambah sampai ke Jakarta dan Bandung. Skor untuk atribut besarnya pemasaran adalah satu (1) yaitu pasar nasional.

\section{Atribut RAPFISH pada Aspek Sosial}

\section{Pertumbuhan Komunitas Nelayan}

Jumlah produksi ikan bilih semenjak tahun 2005 sampai dengan tahun 2008 mengalami peningkatan sebesar $300 \%$. Pada tahun 2010 saat dilakukan penelitian telah mengalami penurunan dibandingkan tahun 2008. Meningkatnya jumlah produksi dan keuntungan yang diterima oleh pelaku usaha penangkapan, menarik perhatian para petani di sekitar Danau Toba untuk beralih menjadi nelayan penangkap ikan bilih. Dengan modal relatif kecil, petani dapat menjadi pelaku usaha penangkap ikan bilih. Dari hasil pengamatan di lapangan, jumlah nelayan mengalami peningkatan semenjak tahun 2005 sampai dengan 2008 dan tetap sampai dengan tahun 2009 serta mengalami penurunan pada tahun 2010. Peningkatan jumlah nelayan semenjak adanya ikan bilih di Danau Toba sampai dengan tahun 2010 sebesar $10 \%$ (skor satu (1)).

\section{Tingkat Pendidikan}

Tingkat pendidikan responden termasuk sedang. Tingkat pendidikan para pelaku usaha adalah SLTP dan SLTA. Tidak ada responden yang mengenyam pendidikan perguruan tinggi. Hal ini disebabkan karena teknologi dalam melakukan penangkapan ikan bilih tidak membutuhkan tingkat pendidikan tertentu, tidak sekolahpun $d$ apat mengoperasikan alat tangkap untuk menangkap ikan bilih. Untuk dapat menjadi pedagang baik pedagang pengumpul dan pedagang besar yang utama dibutuhkan adalah modal, sehingga skor untuk atribut tingkat pendidikan adalah satu (1).

\section{Pengetahuan Lingkungan}

Pengetahuan nelayan terhadap kelestarian lingkungan sangat minim. 
Hal ini dapat dilihat dari cara nelayan melakukan penangkapan ikan. Alat tangkap yang digunakan adalah alat tangkap bagan/ doton dan jaring di muara sungai. Alat tangkap bagan menggunakan alat bantu lampu untuk mengumpulkan bahan makanan sehingga ikan bilih berkumpul untuk mencari makanan. Pemasangan jaring di muara sungai memberikan hasil tangkapan yang lebih banyak dibandingkan di dalam danau, oleh karena itu nelayan berebut untuk dapat melakukan pemasangan jaring di mulut sungai. Nelayan tidak mengetahui bahwa dengan demikian ikan bilih tidak lagi dapat berkembang biak, karena ikan bilih memiliki sifat beruaya ke sungai untuk berkembang biak. Sangat minimnya pengetahuan nelayan ini menyebabkan semakin berkurangnya produksi ikan bilih pada tahun 2010 dibandingkan tahun 2008 dan 2009. Dapat disimpulkan bahwa skor untuk atribut pengetahuan lingkungan dari pelaku usaha penangkapan ikan bilih di Danau Toba adalah nol (0) yaitu sangat minim.

\section{Biaya Hidup Terhadap Total Pendapatan}

Pelaku usaha penangkapan ikan bilih di Danau Toba adalah masyarakat bertempat tinggal di sekitar Danau Toba. Sebagian besar dari masyarakat tersebut adalah masyarakat golongan ekonomi lemah, dimana semua pendapatan digunakan untuk biaya hidup dan sebagian kecil untuk biaya pendidikan. Berdasarkan kriteria RAPFISH dan hasil pengamatan di lokasi penelitian, besaran pendapatan yang digunakan untuk memenuhi biaya hidup lebih dari $80 \%$ (skor dua (2)).

\section{Indeks dan Status Keberlanjutan}

Berdasarkan atribut yang diuraikan diatas, diperoleh indeks keberlanjutan pemanfaatan ikan bilih di Danau Toba dari aspek ekonomi sebesar 46,36\%. Iterasi dilakukan sebanyak 2 kali dengan nilai simpangan baku (stress) sebesar $14 \%$. Nilai R2 yang diperoleh adalah $94,68 \%$.
Mengacu pada selang indeks keberlanjutan Susilo, 2003, maka status keberlanjutan pemanfaatan ikan bilih di Danau Toba termasuk dalam kategori kurang. Pemanfaatan ikan bilih di Danau Toba kurang berkelanjutan dari aspek ekonomi disebabkan karena skor untuk setiap atribut yang digunakan tidak ada yang bernilai baik. Keuntungan yang diterima oleh pelaku perikanan rendah, kontribusi terhadap PDRB sangat kecil, alternatif pekerjaan sangat terbatas, yang tersedia hanya pertanian.

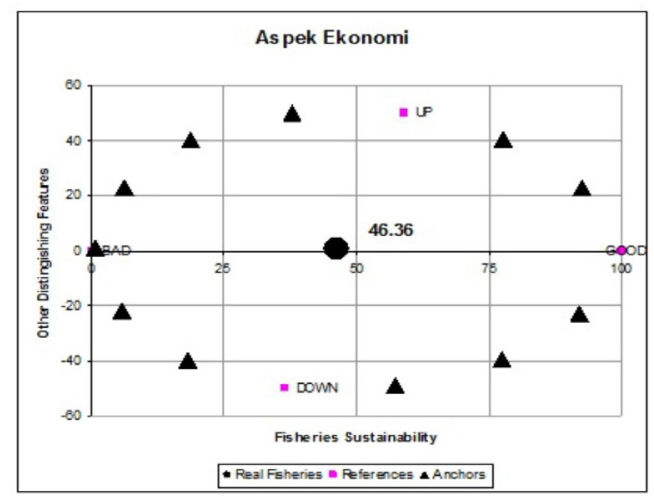

Gambar 2. Posisi Keberlanjutan Pemanfaatan Ikan Bilih Berdasarkan Aspek Ekonomi di Danau Toba, 2010

Figure 2. Position of Sustainability of Bilih Fish Exploitation Based on Economic Aspects in Toba Lake, 2010

Atribut sensitif dari aspek ekonomi ini adalah tingkat subsidi yang diberikan kepada nelayan. Atribut ini menjadi atribut paling sensitif karena atribut ini merupakan salah satu atribut pada aspek ekonomi yang diberikan skor terbaik. Nelayan yang melakukan penangkapan ikan bilih di Danau Toba belum mendapatkan subsidi dalam melakukan usaha penangkapan. Tidak adanya subsidi terhadap pelaku perikanan tangkap akan memberikan dampak yang positif terhadap keberlanjutan usaha perikanan tangkap itu sendiri. Kontribusi perikanan terhadap PDRB juga merupakan atribut sensitif dalam mempengaruhi tingkat keberlanjutan pemanfaatan ikan bilih 
di Danau Toba. Adanya ikan bilih di Danau Toba dalam jumlah yang cukup besar tidak memberikan kontribusi dalam peningkatan PDRB.

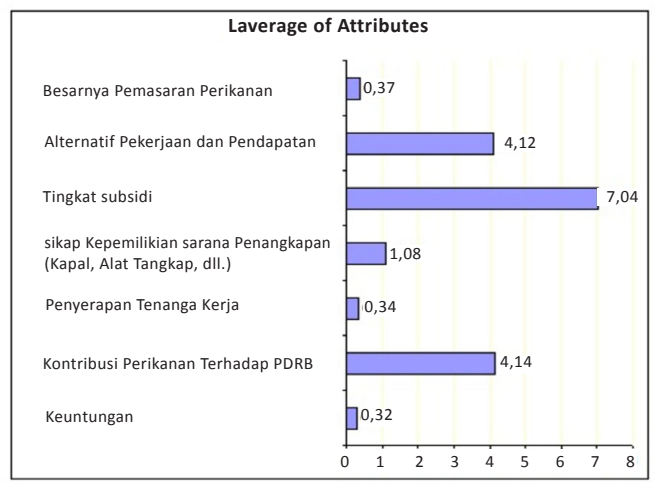

Gambar 3. Analisis Leverage Aspek Ekonomi Pemanfaatan Ikan Bilih di Danau Toba, 2010

Figure 3. Leverage Analysis of Economic Aspects of Bilih Fish Exploitation In Toba Lake, 2010

Indeks keberlanjutan pemanfaatan ikan bilih di Danau Toba ditinjau dari aspek sosial adalah sebesar 31,27\% (Gambar 4).

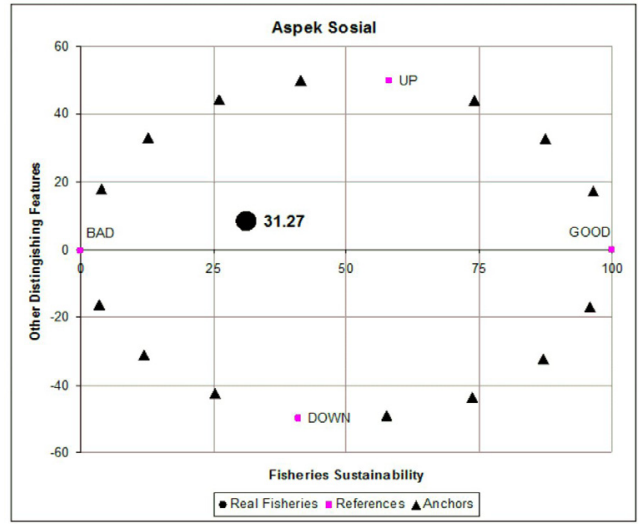

Gambar 4. Posisi Keberlanjutan Pemanfaatan Ikan Bilih berdasarkan Aspek Sosial di Danau Toba, 2010

Figure 4. Position of Sustainability of Bilih Fish Exploitation Based on Social Aspects in Toba Lake, 2010
Dalam RAPFISH, iterasi akan berhenti jika nilai stress telah kurang dari $25 \%$. Iterasi sebanyak 2 kali dengan nilai stress atau simpangan baku sebesar $14,33 \%$. Nilai $R$-square adalah sebesar $95,10 \%$. Status keberlanjutan pemanfaatan ikan bilih di Danau Toba ditinjau dari aspek sosial juga termasuk dalam kategori kurang berkelanjutan. Status demikian disebabkan oleh rendahnya pengetahuan nelayan terhadap pemeliharaan lingkungan dan ekosistem. Nelayan dominan berperilaku untuk dapat memanfaatkan sumber daya ikan bilih secara maksimal, tidak memperhatikan keberlanjutan secara ekologi. Hal ini disebabkan karena rendahnya tingkat pengetahuan dan pendidikan nelayan setempat.

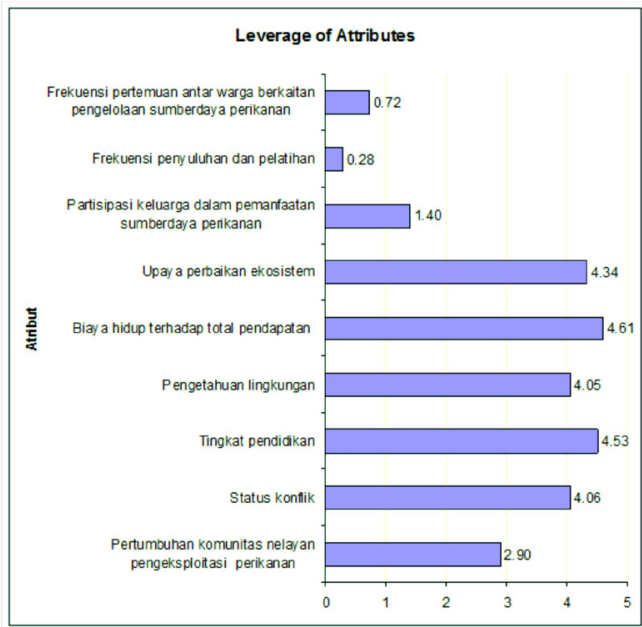

Gambar 5. Analisis Leverage Aspek Sosial Pemanfaatan Ikan Bilih di Danau Toba, 2010

Figure 5. Laverage Analysis of Social Aspects Bilih Fish Exploitation in Toba Lake, 2010

Berdasarkan analisis leverage diperoleh atribut yang sensitif mempengaruhi tingkat keberlanjutan pemanfaatan ikan bilih di Danau Toba adalah tingkat pendidikan nelayan, persentase biaya hidup terhadap total pendapatan dan upaya perbaikan ekosistem. Tingkat pendidikan nelayan masih tergolong rendah, tetapi tingkat 
pendidikan anak nelayan yang melakukan penangkapan ikan bilih sudah jauh lebih baik bahkan dapat mencapai perguruan tinggi. Sebagian besar total pendapatan dari usaha pemanfaatan ikan bilih di Danau Toba digunakan oleh pelaku perikanan untuk memenuhi kebutuhan biaya hidup. Upaya perbaikan ekosistem sangat minim dilakukan oleh nelayan, hal ini disebabkan karena minimnya pengetahuan nelayan terhadap kelestarian sumber daya.

\section{KESIMPULAN DAN IMPLIKASI KEBIJAKAN}

1. Indeks keberlanjutan pemanfaatan sumber daya ikan bilih di Danau Toba dari aspek ekonomi adalah 46,36\% dengan status keberlanjutan dalam kategori kurang. Atribut yang berpengaruh sensitif pada aspek ekonomi adalah tingkat subsidi yang diterima oleh pelaku perikanan di Danau Toba.

2. Indeks keberlanjutan pemanfaatan sumber daya ikan bilih di Danau Toba dari aspek sosial adalah 31,27\% juga dengan status kategori kurang berkelanjutan. Atribut sensitif pada aspek sosial ini adalah persentase biaya hidup terhadap total pendapatan, tingkat pendidikan dan upaya perbaikan ekosistem. Adanya sedikit perubahan terhadap atribut sensitif akan menyebabkan perubahan yang signifikan terhadap indeks keberlanjutan.

3. Keberlanjutan pemanfaatan ikan Bilih di Danau Toba akan terus mengalami penurunan jika tidak ditetapkan suatu skema pengelolaan. Tanpa pengelolaan yang tepat, maka stok ikan Bilih akan terus mengalami penurunan. $\mathrm{Hal}$ ini akan berdampak sangat besar terhadap kehidupan sosial ekonomi masyarakat yang berada di sekitar Danau Toba. Pengelolaan dapat dilakukan dengan menentukan ukuran minimum mata jaring yang diperbolehkan, menetapkan kawasan yang tidak diperbolehkan sebagai tempat penangkapan ikan dan menertibkan penggunaan alat tangkap yang tidak selektif. Dalam menentukan pengelolaan yang ditetapkan, diperlukan adanya koordinasi seluruh kabupaten yang meliputi Danau Toba.

\section{DAFTAR PUSTAKA}

Fauzi, A dan Anna, S. 2005. Pemodelan Sumber Daya Perikanan dan Kelautan. PT. Gramedia Pustaka Utama. Jakarta.

Kartamihardja, E.S. dan A.S. Sarnita. 2008. Populasi Ikan Bilih di Danau Toba: Keberhasilan introduksi ikan dan implikasi pengelolaan dan prospek masa depan. Pusat Riset Perikanan Tangkap, Badan Riset Kelautan dan Perikanan, Departemen Kelautan dan Perikanan. 50 hal.

Kartamihardja, E.S. 2009. Pengelolaan Sumberdaya Ikan Bilih (Mystacoleuscus padangensis) Introduksi di Danau Toba, Sumatra Utara. Jurnal Kebijakan Perikanan Indonesia, Vol 1 (2): 87-98.

Kavanagh, P. 2001. Rapid Appraisal Of Fisheries (RAPFISH) Project : RAPFISH Software Description (For Microsoft Excel). University of British Columbia, Fisheries Centre, Vancouver.

Koeshendrajana, S., Y. D. Sari, E. Reswati dam R. Hapsaridewi. 2010. Valuasi Sosial Ekonomi Dampak Penebaran Ikan Bilih di Danau Toba, Sumatera Utara. Balai Besar Riset Sosial Ekonomi Kelautan dan Perikanan. Jakarta. (Laporan Penelitian ). Unpublish.

Kottelat, M., A.J. Whitten, S.N. Kartikasari and S. Wirjoatmodjo, 1993. Freshwater Fishes of Western Indonesia and Sulawesi - Ikan Air Tawar Indonesia Bagian Barat dan Sulawesi. Periplus Editions, Hong Kong. $344 \mathrm{p}$

Susilo, S. B. 2003. Keberlanjutan Pembangunan Pulau-Pulau Kecil : Studi Kasus Kelurahan Pulau Panggang Dan Pulau Pari, Kepulauan Seribu, DKI Jakarta. Disertasi. Program Pascasarjana Institut Pertanian Bogor. Bogor 